\title{
1 Behaviour of glyphosate in a reservoir and the surrounding 2 agricultural soils
}

4 C. Maqueda, T. Undabeytia, J. Villaverde, E. Morillo*

5 Instituto de Recursos Naturales y Agrobiología de Sevilla (IRNAS-CSIC), Av. Reina

6 Mercedes, 10. Seville, E-41012, Spain.

7

8 Corresponding author: morillo@irnase.csic.es

\section{Abstract}

10 Glyphosate (GPS) is an herbicide currently used on olive crops in Spain, and can be

11 transported to the nearby reservoirs currently used for human consumption. The 12 purpose of this work was to study the behaviour and environmental fate of GPS in water 13 and sediments of the Vibora Reservoir, its tributary river, and the surrounding agricultural soils to assess the risk of water pollution of this reservoir. The adsorption of GPS by different matrices was as follows: heading of the reservoir sediments $($ Cabecera $)>$ tail sediment $($ Cola $)>$ soils $>$ Vibora sediment. The highest amount of oxides (especially $\mathrm{Fe}$ oxides) was observed in sediments from Cabecera and Cola whereas the lowest values were recorded on Vibora sediment. Results indicate that the highest GPS adsorption is due to the amorphous oxides and the edge sites of the clay minerals. Glyphosate adsorption increased with decreasing $\mathrm{pH}$ from 8 to 7 . The desorption percentage of GPS from the four soils studied ranged only from 0.40 to $1.22 \%$. Desorption was almost irreversible for Cabecera and Cola sediments, with values between 0 and $1.1 \%$, respectively. Conversely, Vibora sediment presented about 
$2420 \%$ desorption, probably due to its coarse texture and lower levels of amorphous

25 oxides. Hockey-stick first-order kinetics was the best descriptor for water glyphosate

26 dissipation at the Cabecera and Cola locations, and simple first-order kinetic for the

27 water from the tributary Vibora River. The half-lives (DT50) were between 6.3-11.0

28 days. The rapid degradation of GPS in surface waters and its practically irreversible

29 sorption on these soils and sediments implies that GPS use in similar agricultural areas

30 is of very low environmental risk. This manuscript also outlines the importance of the

31 presence of photo-sensitizers in waters in the degradation routes of GPS in reservoirs.

34 Keywords: Glyphosate, adsorption, dissipation, agricultural soils, reservoir sediments

$36 \quad$ Highlights

37 1. High GPS adsorption to surrounding soils due to amorphous oxides and clay minerals

38 2. Extremely high adsorption capacity of reservoir sediments for GPS

39 3. GPS desorption from soils and sediments almost irreversible.

40 4. High levels of amorphous oxides act as photosensitizers for GPS water dissipation

41 5. High GPS sorption on sediments and dissipation in water reduce its environmental 42 impact 


\section{Introduction}

Monitoring surveys carried out in United States and Europe have indicated that the use of pesticides in agricultural and non-agricultural areas have yielded contamination of surface and groundwater through runoff and soil leaching (Aparicio et al., 2013; Hildebrandt et al., 2008). Many researchers have found a strong correlation between water pollution due to pesticides and agricultural practices in the surrounding areas (Palma et al., 2009; Ricart et al. 2010). Water quality is an important issue in the European Union. The EU has prescribed the maximum concentration of $0.1 \mu \mathrm{g} \mathrm{l}^{-1}$ for each pesticide and of $0.5 \mu \mathrm{g} \mathrm{l}^{-1}$ for the whole in drinking water (Directive 2000/60/EC). Most contaminants released into aquatic environments will be incorporated in sediments, and these sediments might later act as the major source of contaminants released to water and biota.

Glyphosate [ $N$-(phosphonomethyl) glycine] (GPS), is a broad-spectrum, postemergence, non-selective herbicide and very soluble in water $\left(12 \mathrm{~g} \mathrm{l}^{-1}\right)$. It is the world's biggest-selling chemical used for weed control in agricultural, silvicultural and urban environments (Benbrook, 2016), and it is currently used on olive crops in Spain (Cañero et al., 2011). Some authors such as Giesy et al. (2000) and Howe et al. (2004) indicated that GPS is relatively safe environmentally, although nowadays some researchers indicated risks to humans and the environment stemming from applications of glyphosate (Myers et al., 2016). For this reason, the European Union, whose authorization procedure for pesticides is the strictest in the world, has approved a limited extension of the current approval of glyphosate only until the end of 2017, while studies about its carcinogenicity are carried out (European Commission, 2016). In relation to its behaviour in soil, some investigations showed possible leaching and 
toxicity problems with its use (Veiga et al. 2001). Other authors have also shown that soil adsorption and degradation of glyphosate exhibit great variation depending on soil composition and properties (Gimsing et al 2004a; Gimsing et al 2004b; Mamy et al. 2005). Therefore, it is important to study the behaviour and fate of GPS in soils and sediments, including adsorption, dissipation and leaching. GPS is a polar, amphoteric compound that binds strongly to soil. GPS have a soil half-life that range between 2 to 215 days and in aquatic medium is of 2 to 91 days (Battaglin et al., 2014). Predicting the behaviour and transport of an herbicide in soil and sediments involves understanding its adsorption characteristics. Therefore, adsorption coefficients obtained from batch experiments are an important tool for understanding the processes and the prediction of the contaminant behaviour (Wauchope et al., 2002).

There are many papers that describe the factors that control the adsorption of glyphosate on soils and their components (Gimsing et al 2004a; Morillo et al., 2000). However, there is no agreement between the different authors. Glyphosate is a polyprotic acid and forms, within the $\mathrm{pH}$ range of $4-8$ found in most soils, mono- and divalent anions with high affinity for, in particular, trivalent cations such as $\mathrm{Al}^{3+}$ and $\mathrm{Fe}^{3+}$ (Barja and Dos Santos, 2005). GPS can mainly be adsorbed onto variable-charge surfaces and much less onto permanent-charge (negative) sites on layer silicates (Morillo et al., 1997).

Some authors have indicated that adsorption depended mainly on cation exchange capacity (CEC) and clay content (Glass, 1987; de Santana et al., 2006; da Cruz et al. 2007). However, others authors have postulated that iron and aluminium amorphous oxides or organic matter content had the major influence (Morillo et al., 2000; Maqueda et al., 2002, Prata et al., 2005). Some studies have shown that soil adsorption and degradation of GPS exhibit great variation depending on soil 
composition and properties (Sorensen et al., 2006; Gimsing et al., 2007). In addition, the effect of pH on adsorption of GPS in soils and clay minerals is crucial (Morillo et al., 2000; Sheals et al., 2002; Gimsing et al., 2004a; Pessagno et al., 2008). Soil organic matter (SOM) seems to play a controversial and dual role in soil adsorption of GPS. Some authors indicated a negative correlation with GPS adsorption; however, Yu and Zhou (2005) found a great influence of the OM on GPS adsorption. In addition, Maqueda et al. (1998) showed a high GPS adsorption by a natural fulvic acid complex and Piccolo et al. (1996) reported very high adsorption by 4 different purified humus samples, explained by the formation of hydrogen bonding between humus and GPS.

Nevertheless, there is a general agreement in the literature that the adsorption of GPS in soil is governed by the mineral rather than the organic phase (Sheals et al., 2002; da Cruz et al., 2007; Gimsing el al., 2007; Rampazzo et al., 2013). The main soil adsorption sites are found on surfaces of aluminium and iron oxides, especially adsorption by goethite ( $\alpha-\mathrm{FeOOH})$ (Maqueda et al., 2002; Dideriksen and Stipp, 2003), poorly ordered aluminium silicates (allophane/imogolite) and edges of layer silicates. Soils enriched with these variable-charge minerals have been demonstrated to be effective GPS sorbents (Gimsing and Borggaard, 2007), whereas soils dominated by permanent charge minerals such as illite, smectite and vermiculite adsorb less GPS (De Jonge et al. 2001). The layer silicates can contribute with the $\mathrm{OH}$ groups on the octahedral layer.

GPS has a limited risk of leaching to ground water because it is inactivated by strong adsorption in soils and degrades relatively rapidly (Busse et al., 2001; Borgaard and Gimsing, 2008). However, long-term use of GPS may cause surface, ground water and sediments pollution (Kogan et al., 2003; Stewart, 2014). The presence of GPS in natural waters is mainly due to off-site movement via surface waters (Landry et al., 
117 2005; Ibañez et al., 2006; Battaglin et al., 2014). Once GPS has reached the reservoir, it 118 can suffer degradation in water or can be adsorbed to sediments. Microbial degradation 119 of GPS is an important dissipation pathway in surface waters, whereas photolytic decomposition and chemical degradation are comparatively minor (Degenhardt et al., 2012).

The purpose of this work was to study the behaviour and environmental fate of GPS to assess the risk of water pollution of a reservoir taking into account three environmental compartments: water and sediments of the Vibora Reservoir and its tributary river, and their surrounding agricultural soils. As far as we know, most of the previous studies carried out in reservoirs were restricted only to water. Vibora Reservoir is located in a semi-arid region where the main economic activity is the agriculture focused on the cultivation of olive trees. The herbicide GPS was selected because is one of the most used pesticides in olive tree orchards in Spain. The crop yields are strongly dependent on the use of pesticide because of climatic and soil conditions, with a potential risk of water contamination. The herbicides applied to olive crops can be transported to the nearby reservoir currently used for human consumption. Specific attention was given to the adsorption behaviour of GPS in the different media and its contamination of surface waters.

\section{Materials and methods}

\subsection{Pesticide}

High purity glyphosate (98\% purity) was used in adsorption and dissipation 
141 Germany). GPS is a non-residual herbicide, with solubility in water of $12 \mathrm{~g}^{-1}$ at $25^{\circ} \mathrm{C}$.

142 GPS has a zwitterion structure depending on the $\mathrm{pH}$.

\subsection{Sampling site}

Vibora Reservoir is located at the Vibora riverbed in the province of Jaen, in the south of Spain $\left(37^{\circ} 38^{\prime} 8\right.$ "N $3^{\circ} 59^{\prime} 36$ " W). It is a water reservoir for drinking water and fishing and has a capacity of $19 \mathrm{hm}^{3}$. It has a tributary river with the same name, Vibora. In its surrounding environment there are olive trees planting. The province of Jaen is the region with higher olive production concentration in the world and made this zone a proper target to be studied based on the European Framework Water Directive 2000/60/EC (Robles-Molina et al., 2014).

\subsection{Sampling soils, sediments and water}

Four agricultural soils (olive trees) near the Vibora Reservoir were selected for this study. The soils were randomly sampled from the 0-15 cm layer, air dried, and crushed to pass through a $2 \mathrm{~mm}$ sieve before their use in the experiments. Three different sediments were also taken and named as such due to the different locations where they were sampled, Cabecera and Cola (belonging to the head-board and tail of the Víboras Reservoir, respectively) and other one named Vibora, corresponding to the tributary river of the reservoir with the same name. The sediments were taken using a Van Veen grab sampler (0.5-L capacity), and were frozen and lyophilized before carrying out the different determinations. Soils and sediments were analysed for $\mathrm{pH}$ in a water:soil extract at the ratio 2.5:1, total carbonate content, particle size distribution and organic matter $(\mathrm{OM})$ content. The amorphous and organically bound iron, manganese, and aluminium oxides were determined using ammonium oxalate-oxalic acid. 

the reservoir (Cola), and the tributary river Vibora at a depth of $50 \mathrm{~cm}$. Samples were stored in amber bottles in the dark at $4^{\circ} \mathrm{C}$ during transport to the laboratory and then determined in soils, sediments and waters before application of the herbicide, and no residues were found.

\subsection{Mineralogical determination}

The mineralogical determination of the clay fractions $(<2 \mu \mathrm{m})$ of the soils was carried out as described in Maqueda et al. (2015). For soils and sediments, a semiquantitative estimate of clay minerals was determined using the reflection powers given by Schultz (1964).

\subsection{Adsorption-desorption of glyphosate on soils and sediments}

Before performing the batch adsorption experiments, preliminary kinetics studies were carried out. It was found that 24 hours was longer enough to reach GPS adsorption pseudo-equilibrium in soils and sediments. Triplicate adsorption experiments were performed by mixing $5 \mathrm{~g}$ of the different soils with $10 \mathrm{~mL}$ solution containing various concentrations (1-10 $\left.\mathrm{mg} \mathrm{l}^{-1}\right)$ of GPS, in $50 \mathrm{ml}$ polypropylene centrifuge tubes. The samples were shaken on a platform shaker for $24 \mathrm{~h}$ at $20 \pm 1^{\circ} \mathrm{C}$. After shaking, the dispersions were centrifuged and the concentration of GPS in the supernatant was determined. All the experiments were carried out in triplicate. The differences between initial and final herbicide concentrations were assumed to be due to adsorption. The in solution. 

achieved by removing half of the supernatant after centrifugation, then replacing it with distilled water and allowing equilibration for an additional 24-h period. The experiment then proceeded according to the protocol used for the adsorption experiment. This process was repeated twice more. The equilibrium $\mathrm{pH}$ was maintained both in adsorption and desorption isotherms at $\mathrm{pH} 8$ due to the high carbonate content of soils and sediments samples that buffered the medium. Desorption isotherms were obtained representing the amount that remained adsorbed versus the concentration for each desorption process.

Adsorption isotherms were fitted to the Freundlich equation:

$\log \mathrm{Cs}=\log \mathrm{K}_{\mathrm{f}}+\mathrm{n} \log \mathrm{Ce}$

202

where Cs $\left(\mu \mathrm{mol} \mathrm{kg}{ }^{-1}\right)$ is the amount of herbicide adsorbed at the equilibrium concentration $\mathrm{Ce}\left(\mu \mathrm{mol} \mathrm{l}^{-1}\right)$, and $\mathbf{K}_{\mathbf{f}}$ and $\mathrm{n}$ are constants that characterize the relative adsorption capacity and the adsorption intensity, respectively, of the herbicide.

The normalized distribution coefficient $\left(\mathrm{K}_{\mathrm{fOC}}\right)$ of organic carbon $(\mathrm{OC})$ was calculated from the $\mathrm{K}_{\mathrm{f}}$ values $\left(\mathrm{K}_{\mathrm{f}} / \mathrm{OC} \times 100\right)$. The coefficient $\mathrm{K}_{\mathrm{fOC}}$ is often used to characterize the adsorption of non-polar hydrophobic compounds. The concept is based on OC exhibiting the same affinity for a non-polar compound, independent of the source of OC (Morillo et al., 2014). The adsorption distribution coefficients were also determined $\left(\mathrm{K}_{\mathrm{d}}\right)$ at selected $\mathrm{C}_{\mathrm{e}}\left(0.01 \mu \mathrm{mol} \mathrm{l^{-1 }}\right)$. $\mathrm{K}_{\mathrm{f}}$ and $\mathrm{K}_{\mathrm{d}}$ values were used to compare

211 the adsorption capacity of the different matrices. 
adsorption experiments were performed at controlled pHs (7 and 8) by adding aliquots to the different initial solutions of sodium hydroxide or hydrochloric acid such that the final $\mathrm{pH}$ was maintained at that desired. These $\mathrm{pHs}$ were selected because are those usually found in the reservoir along the different seasons. Desorption experiments were carried out in the experiments only at $\mathrm{pH} 8$ for comparison with the soils.

\subsection{Glyphosate dissipation in water under aerobic conditions}

Microbial degradation and photodegradation are routes of GPS dissipation in water. Laboratory experiments were carried out to elucidate the GPS dissipation kinetics in natural water collected from the reservoir and the Vibora tributary river under simulated light exposition. Experimental conditions were selected as closely possible to the natural aquatic environment. Various water samples were brought to our laboratory and premixed before dissipation experiments. Portions of $100 \mathrm{ml}$ of this natural water were distributed in glass containers and GPS was added to obtain a concentration of $2.5 \mathrm{mg} \mathrm{l}^{-1}$. The water samples were placed in a climatic chamber at 25 $\pm 1^{\circ} \mathrm{C}$ with a $16 \mathrm{~h}$ light photoperiod at an intensity of $11 \mu \mathrm{E} \mathrm{m} \mathrm{m}^{-2} \mathrm{~s}^{-1}$. Over 20 days, samples were collected from the containers at different time intervals, the suspensions were filtered through a $0.22-\mu \mathrm{m}$ Millipore glass fibre membrane and the concentration of GPS in the filtrate determined by HPLC-MS. All experiments were carried out in triplicate. A parallel experiment was performed to test potential sorption of GPS to glass surfaces. The operational conditions were identical but using distilled water instead and the containers covered by aluminium foil to prevent photodegradation. No GPS adsorption on the glass container was noticed. 
FOCUS guide (2011), using the least squares method with the SOLVER from the

239 Microsoft Office Excel 2007 mathematical program. Dissipation kinetics were fitted to two models: a simple first-order (SFO) model and a first order sequential model (Hockey-Stick, HS), according to the following equations:

$\mathrm{C}_{\mathrm{t}}=\mathrm{C}_{0} \cdot \mathrm{e}^{-\mathrm{Kt}}$

$C_{t}=C_{0} e^{-k 1 t b} e^{-k 2(t-t b)}$

Where $C_{t}$ is the concentration of pesticide remaining in water $\left(\mathrm{mg} \mathrm{l}^{-1}\right)$ at time $t$ (days);

$\mathrm{C}_{0}$ is the initial concentration of pesticide $\left(\mathrm{mg} \mathrm{l}^{-1}\right) ; \mathrm{K}$ is the rate of dissipation $\left(\right.$ days $\left.^{-1}\right)$.

In the HS model, $\mathrm{k} 1$ and $\mathrm{k} 2$ are the rate constants of dissipation for the fast and the slow $(\times 2)$ test with $\alpha=0.05$ was used to estimate the appropriateness of the model and to assess the accuracy of each resulting fit. This test considers the deviations between observed and estimated values (numerator) for each model in relation to the uncertainty of the measurements (denominator). These models have been selected for consideration based on their relative simplicity and their potential to better fit the measured dissipation kinetics. The time required for 50\% disappearance of GPS (DT50) was determined.

\subsection{Herbicide analysis}

$8 \mathrm{ml}$ of the soil supernatant were subjected to solid-phase-extraction (SPE) on an

261 Oasis HLB $60 \mathrm{mg}$ cartridge, previously conditioned with $2 \mathrm{~mL}$ of methanol and $2 \mathrm{~mL}$ of

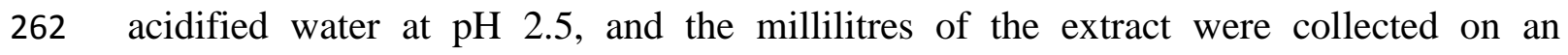


autosampler vial. Recoveries were between $90-97 \%$ for solutions of glyphosate and AMPA of 5 and $10 \mu \mathrm{g} / \mathrm{l}$. The analysis of glyphosate was carried out by liquid chromatography-tandem mass spectrometry in an Agilent HPLC with a triple quadrupole mass detector (ABSciex) under the following conditions: Eluent A, 1\% Acetic acid in Water $+5 \% \mathrm{MeOH}$; eluent $\mathrm{B}, 1 \%$ Acetic acid in $\mathrm{MeOH}$; Column Hypercarb $2.1 \times 100 \mathrm{~mm} 5 \mu \mathrm{m}$ at $40^{\circ} \mathrm{C}$; ionization mode, ESI negative; injection volume, $5 \mu \mathrm{l}$; acquired mass transitions $(\mathrm{m} / \mathrm{z})$ for glyphosate, 168/63, 168/124, 168/150, 168/81; for AMPA, 110/63, 110/79, 110/81; retention times: Glyphosate, 3 min; AMPA, 1.86 min.

The percentage of the eluent A was changed linearly in the time-programmed gradient used as follows: $0 \mathrm{~min}, 100 \%$; $10 \mathrm{~min}, 70 \%$; and $12 \mathrm{~min}, 100 \%$. The flow rate was constant at $0.2 \mathrm{ml} \mathrm{min}^{-1}$. The limits of quantification (LOQ) of both glyphosate and AMPA were $10 \mu \mathrm{g} \mathrm{l}^{-1}$, and their limits of detection (LOD) $3 \mu \mathrm{g}^{-1}$.

\section{Results and Discussion}

\subsection{Physico-chemical and mineralogical characteristics of the soils and sediments}

The physico-chemical characteristics of the studied soils are shown in Table 1. The results indicated that the soils are calcareous with very high carbonate content, especially soils 1,2 and 4 . These soils had basic $\mathrm{pH}$, showed a clay loam texture and typical values of organic matter in Mediterranean semiarid soils. In relation to levels of amorphous oxides, soils 3 and 4 presented the lowest and the greatest amounts, respectively, among the soils studied.

The semiquantitative determination of the clay minerals of the soils is shown in Table 2. The clay fraction of all soils contained mainly illite, but also kaolinite, 
vermiculite, and chlorite are present, except in soil 4 that presented a small amount of smectite instead of chlorite. In general, the mineralogy of the soils is quite similar among them.

The sediments presented also high amount of calcium carbonate and in consequence basic $\mathrm{pH}$, with medium values of $\mathrm{OM}$ similar to the surrounding soils (Table 1). Cola and Cabecera sediments showed similar physico-chemical characteristics. Conversely, the Vibora sediment showed higher values of carbonates. The values of amorphous oxides are slightly higher for Cabecera relative to Cola sediment, whereas the values for Vibora sediment are fairly lower than in the other sediments. The values of OM in sediments are very similar to the values showed by the soils under study. The calcium carbonate content in the sediments was lower for Cabecera and Cola, but was the highest in Vibora sediment. Conversely, the amount of amorphous oxides (especially Fe oxides) was much higher for Cabecera and Cola sediments, about three times higher than for the soils and Vibora sediment. The values of amorphous oxides of Vibora sediment were the lowest. confirmed that the mineralogy of the three sediments was similar, but with different proportions of minerals. They were constituted mainly by calcite, quartz and some feldspar (Table 2). Illite, kaolinite, and vermiculite were also present. Vibora sediment had the highest calcite content in comparison with the other sediments, which explains why this sediment exhibited decreased clay mineral content in relation to the other two sediments. 
312 Fig.1. The isotherms were of "L" type (concave initial curvature). The experimental data were well fitted to the Freundlich equation. The values of Freundlich parameters are listed in Table 3. The correlation coefficients were in all cases greater than $0.98 . \mathrm{n}$ is related to the surface heterogeneity and the diversity of the energies associates with the adsorption reaction. $\mathrm{n}$ values were close to 1 , what could be indicative of low heterogeneity among the sites of the soils where GPS has been adsorbed. It was probably due to the low concentration of herbicide used in the adsorption isotherms experiments, implying that GPS was adsorbed on high affinity sites, which were not totally occupied in the range of concentrations used. Because $\mathrm{n}$ values were very similar on the edges positions. However, Glass (1987) postulated that adsorption of GPS by 
between soil 4 and the others was the presence of smectite, amounting at about $10 \%$,

which also would increase the CEC.

The role of hydrophobic bonds in the adsorption of non-polar hydrophobic herbicides to soils can be compared by normalizing the Freundlich adsorption parameter to the percentage of organic carbon $\left(\mathrm{K}_{\mathrm{foc}}\right)$ in each sample. A more hydrophobic molecule results in a greater probability of partitioning from the aqueous phase to the organic phase. For comparison among soils, the $\mathrm{K}_{\text {foc }}$ parameter can be used as a measure of this property in soils, and it is independent of other soil properties. For a specific pesticide, when hydrophobic bonds are the only factor responsible for its adsorption, the $\mathrm{K}_{\text {foc }}$ values should be relatively constant among the different soils. However, the values obtained in this study are quite different (Table 3), ranged from 7332 to 14263 , indicating that the adsorption mechanism is related to some other soil properties in addition to the OC content (Morillo et al., 2002; Undabeytia et al., 2011; Rubio-Bellido et al., 2016). Morillo et al. (2000) observed that GPS adsorption to three soils of different characteristics was not related to their CEC and clay mineral content, but to levels of iron and aluminium amorphous oxides and organic matter. In this work soil 4 presented the greatest value of amorphous oxides of the four studied soils (Table 1), which could be a factor worthwhile considering the greatest adsorption of GPS in this soil. The fact that GPS adsorption follows the same pattern as total amorphous oxide content in these soils seems to indicate that the main soil adsorption sites are found on the variable-charge surfaces of such amorphous oxides.

GPS desorption from soils was very little. Table 4 shows the total percentages of GPS desorbed (after three cycles of desorption) from the soil samples treated with GPS 3, 5 and $10 \mathrm{mg}^{-1}$. The adsorption was almost irreversible in the four soils, indicating a 
strong hysteresis. Al-Rajab et al. (2008) indicate that adsorption and desorption were depended on $\mathrm{pH}$ only but not to the initial quantity of glyphosate adsorbed to the soil. However, other authors showed that in general the more the sorption of GPS the more reversible it was, indicating that GPS was more strongly adsorbed when the surface coverage was small (Okada et al., 2016). In this work the values of desorption were very similar for the different points of adsorption although a little higher for the points with higher adsorption. The percentage of GPS desorbed for the 4 studied soils ranged between 0.40 to $1.22 \%$.

Piccolo et al (1996) indicated that desorption of GPS was the inversely related to its adsorption and a large part of the adsorbed herbicide can be easily returned to the soil solution with desorption from around $15 \%$ to $80 \%$ of the adsorbed GPS, contrary to the behaviour in our soils. The reason of such behaviour could be that the maximum GPS used in in the present work was $20 \mu \mathrm{g} \mathrm{g}^{-1}$ and in Piccolo et al. (1996) was $7.5 \mathrm{mg} \mathrm{g}^{-1}$. In such case de desorption of GPS was carried out not only from high affinity sites, but also in positions where the interactions were very weak and from which the herbicide was easily desorbed. According with our results, Farenhorst et al. (2009) observed also that GPS was relatively immobile in experiments carried out using 90 soils from different depths in the soil profile, even under rainfall scenario $(384 \mathrm{~mm})$ when GPS had been applied at recommended field rates. This behaviour was also confirmed by Bergstrom et al. (2011) who observed in a lysimeter study that $59 \%$ of the initial amount of GPS added to a clay soil was present after 748d after application; also Okada et al. (2016) obtained less than $0.24 \%$ of the applied pesticide leached in the whole set of soils studied.

The presence of AMPA was not detected in these adsorption-desorption studies. The complete sorption-desorption experiments were performed in shorter time (4 days) 
than the half-life times usually recorded (15-23.8 days, IUPAC Pesticide Properties Data Base).

\subsection{GPS adsorption-desorption on sediments}

The adsorption experiments of GPS in the three studied sediments were carried out at controlled pHs of 7 and 8 by addition of $\mathrm{NaOH}$ or $\mathrm{HCl}$ aliquots to the different initial concentrations in order to obtain equilibrium $\mathrm{pHs}$ similar to $\mathrm{pH}$ levels found in the reservoir throughout the year. The adsorption isotherms of Cabecera, Cola and Vibora sediments at pHs 7 and 8 are shown in Figure 2. The adsorption isotherms of the sediments are presented in separated figures due to the large difference in the amount of GPS adsorbed by Cabecera and Cola sediments in comparison with Vibora sediment. GPS adsorption in Cabecera and Cola sediments were not well described by the linearized Freundlich equation. In the case of Vibora, the $\mathrm{K}_{\mathrm{f}}$ values obtained were 212 (n, 0.9558; $\left.\mathrm{R}^{2} 0.9762\right)$ and $46.2\left(\mathrm{n}, 0.9376 ; \mathrm{R}^{2} 0.9098\right)$ for $\mathrm{pHs} 7$ and 8 , respectively. These values are similar to those obtained for the studied soils (Table 3).

As equilibrium concentrations reached in Cabecera and Cola sediments were very low, distribution coefficient $(\mathrm{Kd})$ for the three sediments were calculated at an equilibrium concentration of $0.01 \mu \mathrm{mol} \mathrm{l}^{-1}$ to compare the capacity of the different sediments to adsorb GPS (Table 5). The GPS adsorption by these sediments was almost complete at an equilibrium $\mathrm{pH}$ of 7 . The Kd values for GPS adsorption to sediments ranged from 67.3 (Vibora $\mathrm{pH}$ 8) to 11800 (Cabecera $\mathrm{pH}$ 7). According with $\mathrm{Kd}$ values the order of GPS adsorption to sediments was as follows: 

values (in the range 4810-11800) in comparison with Vibora sediment (67.3 and 404). This behaviour could be related with several physicochemical properties. First of all, the higher amorphous oxides values in these two sediments in comparison with Vibora (almost four times higher, Table 1) and also with the soils previously studied (about three times higher). According to Morillo et al. (2000), the possible adsorption mechanism of the GPS to the oxides and hydroxides of soils and sediments as well as to the surfaces of variable charge on the organic matter is through the formation of bonds adsorbent-metal-phosphonic group of GPS. Thus, amorphous Fe- and Al-oxides, in general, seem to be a key parameter for glyphosate adsorption in soils (Rampazzo et al., 2013; Ololade et al., 2014; Paradelo et al., 2015; Sidoli et al., 2016). Secondly, the clay minerals content is very low in Vibora in comparison to the other two sediments (Table 2) providing lower amount of charge variable sites located on the edge broken bonds. According to Farenhorst et al. (2009) GPS adsorption was lower in soils with lower clay content, even if those contained more OM. And finally, Vibora sediment presented a loamy sand texture, and Cabecera and Cola sediments present a silt loam texture, providing much higher surfaces for adsorption. To the best of the authors' knowledge, this is the first study where GPS adsorption to sediments presented such high values, and this is due to the previous arguments. Therefore, a higher GPS adsorption is observed in Cabecera than in Cola sediment, due both to its higher amorphous oxides (Table 1) and clay minerals contents (Table 2).

$430 \mathrm{Kd}$ values were also calculated for GPS adsorption to the soils under study (carried out at $\mathrm{pH}$ 8) at an equilibrium concentration of $0.01 \mu \mathrm{mol} \mathrm{l}^{-1}$, in order to compare their adsorption capacity with that of the sediments. Soil Kd values ranged from 197 to 213 , 
433 indicating that adsorption was more similar to that observed in Vibora sediment as compared to Cabecera and Cola sediments (Table 5).

435 Glyphosate adsorption increased with decreasing $\mathrm{pH}$ from 8 to 7 . The effect of $\mathrm{pH}$ may be due to the influence on the charge of the GPS molecule and the surface charge of the adsorbent (Gimsing et al. 2007). A decrease in pH facilitates the adsorption of GPS in sediments which pose a high content of oxides, because when $\mathrm{pH}$ decreases the variable charge surface of the oxides is more protonated. Therefore, the adsorption of negatively charged species of GPS will be favoured. In addition, there is also a reduction in the amount of ionized acid functional groups over the surface of the organic matter, enhancing GPS sorption. Moreover, there is a slight difference in GPS species in solution at $\mathrm{pH} 7$ and 8 attending to GPS pKa values that drives larger sorption at the lower $\mathrm{pH}$. The concentration of negatively charged species is reduced about $2-3 \%$ at $\mathrm{pH}$ 7 relative to pH 8 (Saitúa et al., 2012).

In spite of the high amount of studies dealing with GPS adsorption to soils, its adsorption to sediments has been poorly studied and understood, especially in reservoir sediments, where it is very interesting to know the behaviour of this herbicide in relation to the quality of freshwater ecosystems. The scarce studies carried out are related to GPS content in wetland sediments (Xu et al., 2009; Degenhardt et al., 2012) but only some works deal with GPS adsorption to sediments. Dollinger et al. (2015), in a review about GPS adsorption in soils and sediments, presented GPS adsorption parameters on sediments from France, Canada and Germany with different physico454 chemical properties (Bailly et al., 2015; Xu et al., 2009; Litz et al., 2011). In these studies, $\mathrm{K}_{\mathrm{f}}$ values ranged from 1.89 to $319 . \mathrm{K}_{\mathrm{f}}$ for Vibora sediment is included in this range: 46.2 and 212 for GPS adsorption at $\mathrm{pH} 8$ and 7, respectively. However, none of the mentioned sediments showed so high adsorption as Cabecera and Cola sediments. 

sediments (Table 6). It is almost irreversible for Cabecera and Cola sediments, with values from $0 \%$ to $1.1 \%$, while in Vibora about $15-20 \%$ GPS was desorbed. It could be related with its coarse texture and the much lower amount of amorphous oxides in Vibora sediment. There is also difference between Vibora GPS desorption and that observed previously for soils (about 1\%), due to their clay loam texture in comparison to the loamy sand texture of Vibora sediment, with lower surfaces and, therefore, less adsorption sites.

\subsection{Dissipation of GPS in water under aerobic conditions}

The kinetics of GPS degradation in water at the same places where the different studied sediments were taken is shown in Figure 3, and the corresponding kinetic parameters are presented in Table 7 . In these studies, the degradation of glyphosate to 471 its major metabolite AMPA was monitored but the remaining amount in water was below the LOQ of the analytical technique, and after 11 days under the LOD.

$\mathrm{DT}_{50}$ values obtained for Cabecera and Cola water dissipation were 6.3 and 6.4 days, respectively, and 11.0 for Vibora water. These data are in agreement with those reported by other authors for natural water dissipation. Mallat and Barcelo (1998) indicated that the main factors affecting the degradation of glyphosate in water can be summarized as a combination of microbial activity, temperature and, to a lesser extent, photolysis. 478 These authors indicated that the degradation of glyphosate is fast under natural 479 conditions, for ground water and river water samples half-lives were $60 \mathrm{~h}$ and $100 \mathrm{~h}$, respectively. The complexity of the water matrix is an important factor to take into account since it can change the degradation rate of glyphosate. Goldsborough and Brown (1993) reported that dissipation of glyphosate and aminomethylphosphonic acid 
in water and sediments of boreal forest ponds is typically rapid with first-order $\mathrm{DT}_{50}$ values ranging from 3.5 to $11.2 \mathrm{~d}$.

The more rapid dissipation observed in the case of Cabecera and Cola water in relation to Vibora could be due to indirect photolysis through photosensitizers. Shifu et al. (2007) showed that GPS is easily degraded by assisted photocatalysis in aqueous dispersion under radiation by UV light. Assalin et al. (2010) observed half-lives for GPS degradation of 6.2 minutes for $\mathrm{TiO}_{2} / \mathrm{UV}$ irradiation. Although GPS is difficult to dissipate via direct photodegradation by sunlight, many iron complexes have photoactivity and various iron species are abundant in natural water (Chen et al., 2007). Iron oxides were proposed as photocatalysts because of their semiconductor properties (Bandara et al., 2001). The suspended solids in these natural waters which are the finer fraction of the sediments will have a high content of iron oxides acting as a photosensitizer and explaining the rapid GPS dissipation.

\section{Conclusions}

The results of this study indicate high GPS adsorption capacity of the soils surrounding the Vibora Reservoir due to their high amorphous oxides and clay mineral content. GPS adsorption follows the same sequence as total amorphous oxide content.

501 GPS adsorption to sediments has been poorly studied and understood, especially in reservoir sediments, which is very interesting to know the behaviour of this herbicide in relation to the quality of freshwater ecosystems. In the present study, those sediments taken from the heading and tile of the reservoir showed extremely high adsorption capacity, with $\mathrm{Kd}$ values in the range 4810-11800 in comparison to the adsorption to 
507 those values observed in the surrounding soils. The adsorption of GPS to the different 508 matrices was as follows: heading of the reservoir sediments (Cabecera) $>$ tile sediments 509 (Cola) $\gg>>$ soils > Vibora sediment. To the best of the authors' knowledge, this is the 510 first study where GPS adsorption to sediments presented such high values, and this is 511 due especially to the amount of oxides (especially Fe oxides) present in such sediments, 512 which was about three-fold higher for Cabecera and Cola sediments than for the soils and Vibora sediment. In addition, Cabecera and Cola sediments presented a fine texture 514 (silt loam) providing much higher surfaces for adsorption. Glyphosate adsorption to 515 sediments increased with decreasing $\mathrm{pH}$ from 8 to 7 , due to an increasing positive 516 charge on the sediment surfaces and to the formation of GPS species with lower 517 negative charge, which are adsorbed more easily to the negatively charged surfaces of 518 the sediments.

519 GPS desorption for the studied soils and sediments were almost irreversible, percentages ranging from 0 to $1.22 \%$, except in Vibora sediment, which presented 15$20 \%$ desorption, probably due to its coarse texture (loamy sand) and much lower level 522 of amorphous oxides.

523 The dissipation of glyphosate in the water from the same places where the different 524 studied sediments were taken was also studied. The $\mathrm{DT}_{50}$ values obtained for water 525 from Cabecera and Cola were 6.3 and 6.4 days, respectively; for Vibora, this value was 52611 days. The more rapid dissipation observed in the case of Cabecera and Cola water 527 could be due to indirect photolysis through photosensitizers. The suspended solids in 528 these natural waters coming from the finer fraction of the sediments are likely to have 529 high levels of iron oxides acting as photosensitizers and explaining the rapid GPS 530 dissipation. 
531 The importance of the contribution of sediments from reservoirs to the behaviour of

532 glyphosate is pointed out in this paper because there is limited information available in

533 the literature. The rate of GPS degradation in the water from Vibora Reservoir was very

534 rapid, decreasing the potential risk impact on the aquatic ecosystem. This behaviour

535 together with the almost irreversible adsorption of GPS from its sediments and the

536 surrounding soils indicate the low toxicity risk of GPS in this zone, where this herbicide

537 is widely used for olive crops.

\section{Acknowledgments}

540 This work was supported by the Spanish Ministry of Economy and Competitiveness

541 (co-funded by the Fondo Europeo de Desarrollo Regional, FEDER), under the research 542 project CTM2013-42599-R and Junta de Andalucía Proyect RNM 894.

\section{REFERENCES}

545 Al-Rajab, A.J., Amellal, S., Schiavon, M. 2008. Sorption and leaching of 14C546 glyphosate in agricultural soils. Agron. Sustain. Dev. 28, 419-428.

547 Aparicio, V.C., De Geronimo, E., Marino, D., Primost, J. Carriquiriborde, P., Costa, 548 J.L. 2013. Environmental fate of glyphosate and aminomethylphosphonic acid in 549 surface waters and soil of agricultural basin. Chemosphere 93, 1866-1873.

550 Assalin, M.R., de Moraes, S.G., Queiroz, S.C.N., Ferracini, V.L., Duran, N. 2010.

551 Studies on degradation of glyphosate by several oxidative chemical processes: 
552 Ozonation, photolysis and heterogeneous photocatalysis. J. Environ. Sci. Health B 45, $553 \quad 89-94$.

554 Bailly, J.S., Dages, C., Dollinger, J., Lagacherie, P., Voltz, M. 2015. Protocole de 555 spatialisation et d'e'volution d'e'tats de surface de fosse's. French Government Water 556 and Aquatic Bodies Office, 60 p.

557 Bandara, J., Mielczarski, J.A., Lopez, A., Kiwi, J., 2001. Sensitized degradation of 558 chlorophenols on iron oxides induced by visible light. Comparison with titanium oxide. 559 Appl. Catal. B 34, 321-333.

560 Barja, B.C., Dos Santos Afonso, M. 2005. Aminomethylphosphonic acid and 561 glyphosate adsorption onto goethite: a comparative study. Environ. Sci. Technol. 39, $562 \quad 585-592$.

563 Battaglin, W.A. , Meyer, M.T., Kuivila, K.M., Dietze, J.E. 2014. Glyphosate and its 564 degradation product AMPA occur frequently and widely in U.S. soils, surface water, 565 groundwater, and precipitation. J. Am. Water Resources Assoc. 50, 275-290.

566 Bergstrom, L., Borjessom, E., Stenstrom, J. 2011. Laboratory and lysimeter studies of 567 glyphosate and aminomethylphosphonic acid in a sand and a clay soil. J. Environ. Qual. $568 \quad 40,98-108$.

569 Benbrook, C.M. 2016. Trends in glyphosate herbicide use in the United States and 570 globally. Environ. Sci. Eur. 28, 3, DOI: 10.1186/s12302-016-0070-0.

571 Borgaard, O.K., Gimsing, A.L. 2008. Fate of glyphosate in soil and the possibility of 572 leaching to ground and surface water: a review. Pest Manag. Sci. 64, 441-456. 
573 Busse, M.D., Ratcliff, A.W., Shestak, C.J., Powers, R.F. 2001. Glyphosate toxicity and 574 effects of long-term vegetation control on soil microbial communities. Soil Biol. 575 Biochem. 33, 1777-1789.

576 Cañero, A., Cox, L., Redondo-Gomez, S., Mateos-Naranjo, E., Hermosín, M.C., 577 Cornejo, J. 2011. Effect of the Herbicides Terbuthylazine and Glyphosate on 578 Photosystem II Photochemistry of Young Olive (Olea europaea) Plants. J. Agric Food 579 Chem. 59, 5528-5534.

580 Chen, Y., Wu, F., Lin, Y., Deng, N., Bazhin, N., Glebov, E. 2007. Photodegradation of 581 glyphosate in the ferrioxalate system. J. Hazard. Mater. 148, 360-365.

582 Da Cruz, H.L., De Santana, H., Zaia, C.T.B.V., Zaia, D.A.M. 2007. Adsorption of 583 Glyphosate on Clays and Soils from Paraná State: Effect of $\mathrm{pH}$ and Competitive 584 Adsorption of Phosphate. Brazilian Arch. Biol. Technol. 503,385-394.

585 De Santana, H., Toni, L.R.M., Benetoli, L.O.B., Zaia, C.T.B.V., Rosa Jr., M., Zaia, 586 D.A.M. 2006. Effect in glyphosate adsorption on clays and soils heated and 587 characterization by FT-IR spectroscopy. Geoderma 136, 738-750. of glyphosate and aminomethylphosphonic acid in water and sediment of two Canadian 590 prairie wetlands. J. Environ. Sci. Health B 47, 631-639.

591 De Jonge, H., de Jonge, L.W., Jacobsen, O.H., Yamaguchi, T., Moldrup, P. 2001. 592 Glyphosate sorption in soils of different pH and phosphorus content. Soil Sci. 166, 230$593 \quad 238$ 
594 Dideriksen, K., Stipp, S.L. 2003. The adsorption of glyphosate and phosphate to 595 goethite: a molecular-scale atomic force microscopy study. Geochim. Cosmochim. 596 Acta, 67, 3313-3327.

597 Directive 2000/60/EC of the European Parliament and of the Council, of 23 October 598 2000, establishing a framework for community action in the field of water policy. Off. 599 J. Eur. Communities, L327, 01-72.

600 Dollinger, J., Dagès, C., Voltz, M. 2015. Glyphosate sorption to soils and sediments 601 predicted by pedotransfer functions. Environ. Chem. Letters 13, 293-307.

602 European Commission. 2016. Glyphosate: Commission proposes the way forward (via 603 de avance)-Statement by Commissioner for health and Food Safety. 604 http://europa.eu/rapid/press-release_STATEMENT-16-2011_en.htm

605 Farenhorst, A., McQueen, D.A.R., Saiyed, I. Hilderbrand, C., Li, S., Lobb, 606 D.A, Messing, P., Schumacher, T.E, Papiernik, S.K., Lindstrom, M.J. 2009. 607 Variations in soil properties and herbicide sorption coefficients with depth in relation to 608 PRZM pesticide root zone model calculations. Geoderma 150, 267-277.

609 FOCUS Guide 2011. Forum for the Co-ordination of pesticide fate models and their 610 Use. Guidance Document on Estimating Persistence and Degradation Kinetics from 611 Environmental Fate Studies on Pesticides in EU Registration. Work Group on 612 Degradation Kinetics. Generic guidance for estimating persistence and degradation 613 kinetics from environmental fate studies on pesticides in EU registration, 1.0 edition, 614434 pp. In: http://focus.jrc.ec.europa.eu/dk (accessed on 05/22/16).

615 Giesy J.P., Dobson, S., Solomon, K.R. 2000. Ecotoxicological risk assessment for 616 Roundup herbicide. Rev. Environ. Contam. Toxicol. 167, 35-120. 
617 Gimsing, A.L., Borggaard, O.K., Bang, M., 2004a. Influence of soil composition on 618 adsorption of glyphosate and phosphate by contrasting Danish surface soils. Eur. J. Soil 619 Sci. 55, 183-191.

620 Gimsing, A.L., Borggaard, O.K., Jacobsen, O.S., Aamand, J., Sørensen, J. $2004 b$. 621 Chemical and microbial soil characteristics controlling glyphosate mineralisation in 622 Danish surface soils. Appl. Soil Ecol. 27, 233-242.

623 Gimsing, A.L., Borggaard, O.K. 2007. Phosphate and glyphosate adsorption by 624 hematite and ferrihydrite and comparison with other variable-charge minerals. Clays 625 Clay Miner. 55,110-116.

626 Gimsing, A.L., Szilas, C., Borggaard, O.K. 2007. Sorption of glyphosate and phosphate 627 by variable-charge tropical soils from Tanzania. Geoderma 138, 127-132.

628 Glass, R.L. 1987. Adsorption of glyphosate by soils and clay minerals. J. Agric. Food 629 Chem. 35, 497-500.

630 Goldsborough, L.G., Brown, D.J. 1993. Dissipation of glyphosate and 631 aminomethylphosphonic acid in water and sediments of boreal forest ponds Environ. 632 Toxicol. Chem. 12, 1139-1147.

633 Hildebrandt, A., Guillamon, M., Lacorte, S., Tauler, R., Barcelo,D. 2008. Impact of 634 pesticides used in agriculture and vineyards to surface and groundwater quality (North 635 Spain). Water Res. 42, 3315-3326.

636 Howe, C.M., Berrill, M., Pauli, B.D., Helbing, C.C., Werry, K., Veldhoen, N. 2004. 637 Toxicity of glyphosate-based pesticides to four North American frog species. Environ. 638 Toxicol. Chem. 23, 1928-1938. 
639 Ibañez, M., Pozo, O.J., Sancho, J.V., Lopez, F.J., Hernandez, F. 2006. Re-evaluation of 640 glyphosate determination in water by liquid chromatography coupled to electrospray 641 tandem mass spectrometry. J. Chromatogr. A, 1134, 51-55.

642 Kogan, M., Metz, A., Ortega, R. 2003. Adsorption of glyphosate in Chilean soils and its 643 relationship with unoccupied phosphate binding sites. Pesquisa Agropecuaria Brasileira $644 \quad 38,513-519$

645 Landry, D., Dousset, S., Fournier, J.C., Andreux, F. 2005. Leaching of glyphosate and 646 AMPA under two soil management practices in Burgundy vineyards (Vosne-Roman'ee, 647 21-France). Environ. Pollut. 138, 191-200.

648 Litz, N.T., Weigert, A., Krause, B., Heise, S., Grützmacher, G. 2011. Comparative 649 studies on the retardation and reduction of glyphosate during subsurface passage. Water 650 Res. 45, 3047-3054.

651 Mallat, E., Barcelo, D. 1998. Analysis and degradation study of glyphosate and of 652 aminomethylphosphonic acid in natural waters by means of polymeric and ion653 exchange solid-phase extraction columns followed by ion chromatography-post-column 654 derivatization with fluorescence detection . J. Chromatogr. A . 823, 129-136. Mamy, L., Barriuso, E., Gabrielle, B. 2005. Environmental fate of herbicides trifluralin, metazachlor, metamitron andsulcotrione compared with that of glyphosate, a substitute broad spectrum herbicide for different glyphosate-resistant crops. Pest Manag. Sci. 61, 658 905-916.

Maqueda, C; Morillo, E; Undabeytia, T, Martín, F. 1998. Sorption of glyphosate and $660 \mathrm{Cu}(\mathrm{II})$ on a natural fulvic acid complex: Mutual influence. Chemosphere 37, 1063661 1072. 
662

663

664

665

666

667

668

669

670

671

672

673

674

675

676

677

678

679

680

681

682

683

684

Maqueda, C., Morillo, E., Undabeytia, T. 2002. Cosorption of glyphosate and copper (II) on goethite. Soil Sci. 167, 659-665.

Maqueda, C., Morillo, E., Lopez, R., Undabeytia, T., Cabrera, F. 2015. Influence of organic amendments on $\mathrm{Fe}, \mathrm{Cu}, \mathrm{Mn}$, and $\mathrm{Zn}$ availability and clay minerals of different soils. Archives of Agronomy and Soil Science 61, 599-613.

Morillo, E., Undabeytia, T., Maqueda, C. (1997) Adsorption of glyphosate on the clay mineral montmorillonite: Effect of $\mathrm{Cu}(\mathrm{II})$ in solution and adsorbed on the mineral. Environ. Sci. Technol. 31, 3588-3592.

Morillo, E., Undabeytia, T., Maqueda, C., Ramos, A. 2000. Glyphosate adsorption on soils of different characteristics. Influence of copper addition. Chemosphere 40, 103107.

Morillo, E., Undabeytia, T., Maqueda, C., Ramos, A. 2002. The effect of dissolved glyphosate upon the sorption of copper by three selected soils. Chemosphere 47, 747752.

Morillo, E., Sanchez-Trujillo, M.A., Villaverde, J., Madrid, F., Undabeytia, T. 2014. Effect of contact time and the use of hydroxypropyl- $\beta$-cyclodextrin in the removal of fluorene and fluoranthene from contaminated soils. Sci. Total Environ. 496, 144-154.

Myers, J.P., Antoniou, M.N., Blumberg, B., Carroll, L., Colborn, T., Everett, L.G., Hansen, M., Landrigan, P.J., Lanphear, B.P., Mesnage, R. 2016. Concerns over use of glyphosate-based herbicides and risks associated with exposures: a consensus statement. Environ. Health 15, 117.

Okada, E., Costa, J.L., Bedmar, F. 2016. Adsorption and mobility of glyphosate in different soils under no-till and conventional tillage. Geoderma 263, 78-85. 
685 Ololade, I.A., Oladoja, N.A., Oloye, F.F., Alomaja, F., Akerele, D.D., Iwaye, J., 686 Aikpokpodion, P. 2014. Sorption of Glyphosate on Soil Components: The Roles of 687 Metal Oxides and Organic Materials. Soil Sediment Contam. 23, 571-585.

688 Palma, P., Kuster, M., Alvarenga, P., Palma, V.L, Fernandes, R.M., Soares, 689 A.M.V.M, López de Alda, M.J., Barceló, D., Barbosa, I.R. 2009. Risk assessment of 690 representative and priority pesticides, in surface water of the Alqueva reservoir (South 691 of Portugal) using on-line solid phase extraction-liquid chromatography-tandem mass 692 spectrometry. Environ. Intern. 35: 545-551.

693 Paradelo, M., Norgaard, T., Moldrup, P., Ferré, T.P.A., Kumari, K.G.I.D., Arthur, E., 694 De Jonge, L.W. 2015. Prediction of the glyphosate sorption coefficient across two 695 loamy agricultural fields. Geoderma 259-260, 224-232.

696 Pessagno, R.C., Torres Sánchez, R.M., dos Santos Afonso, M. 2008. Glyphosate 697 behavior at soil and mineral-water interfaces. Environ. Pollut. 153, 53-59.

698 Piccolo, A., Celano, G., Conte, P. 1996. Adsorption of glyphosate by humic substances. 699 J. Agric. Food Chem. 44, 2442-2446.

700 Prata, F., Lavorenti, A., Regitano, J.B., Tornisielo, V.L., Pelissari, A. 2005. Glyphosate 701 behavior in a Rhodic Oxisol under no-till and conventional agricultural systems. Revista 702 Brasileira de Ciencia do Solo. 29, 61-69.

703 Rampazzo, N., Todorovic, G., Mentler, A., Blum, W.E.H. 2013. Adsorption of 704 glyphosate and aminomethylphosphonic acid in soils. Int. Agrophys. 27, 203-209.

705 Ricart, M., Guasch, H., Barceló, D., Brix, R., Conceicao, M.H., Geiszinger, A., M.J. 706 López de Alda, López-Doval, J.C., Muñoz, I., Postigo, C., Romaní, A.M., Villagrasa, 
M., Sabater, S. 2010. Primary and complex stressors in polluted mediterranean rivers: pesticide effects on biological communities. J. Hydrol. 383, 52-61.

Robles-Molina, J., Gilbert-López, B., García-Reyes, J.F., Molina, A. 2014. Monitoring of selected priority and emerging contaminants in the Guadalquivir River and other related surface waters in the province of Jaén, South East Spain. Sci. Total Environ. 479-480, 247-257.

Rubio-Bellido, M., Morillo, E., Villaverde, J. 2016. Effect of addition of HPBCD on diuron adsorption-desorption, transport and mineralization in soils with different properties. Geoderma 265, 196-203.

Saitúa, H., Giannini, F., Padilla, A.P. 2012. Drinking water obtaining by nanofiltration from waters contaminated with glyphosate formulations: Process evaluation by means of toxicity tests and studies on operating parameters. J. Hazard. Mater. 227-228, 204210.

Schultz, L.G. 1964. Quantitative interpretation of mineralogical composition from xray and chemical data for Pierre Shale. U.S. Geol Surv. Prof. Pap. 391-C.

Sheals, J., Sjoberg, S., Persson, P. 2002. Adsorption of glyphosate on goethite: molecular characterization of surface complexes. Environ. Sci. Technol. 36, 3090-3095.

Shifu, C., Yunzhang, L. 2007. Study on the photocatalytic degradation of glyphosate by $\mathrm{TiO}_{2}$ photocatalyst. Chemosphere 67, 1010-1017.

Sidoli, P., Baran, N., Angulo-Jaramillo, R. 2016. Glyphosate and AMPA adsorption in soils: laboratory experiments and pedotransfer rules. Environ. Sci. Pollut. Res. 23, $5733-5742$. 
Sørensen, S.R., Schultz, A., Jacobsen, O.S., Aamand, J. 2006. Sorption, desorption and mineralisation of the herbicides glyphosate and MCPA in samples from two Danish soil and subsurface profiles. Environ. Pollut. 141, 184-194.

Stewart, M., Olsen G., Hickey, C.W., Ferreira, B., Jelić, A., Petrović, M., Barcelo, D. 2014. A survey of emerging contaminants in the estuarine receiving environment around Auckland, New Zealand. Sci. Total Environ. 468, 202-210.

Undabeytia, T., Recio, E., Maqueda, C., Sánchez-Verdejo, T., Balek, V. 2011. Slow diuron release formulations based on clay-phosphatidylcholine complexes. Appl. Clay Sci. 55, 53-61.

Veiga, F., Zapata, J.M., Marcos, M.L.F., Alvarez, E. 2001. Dynamics of glyphosate and aminomethylphosphonic acid in forest soil in Galicia, north-west Spain. Sci. Total Environ. 271, 135-144.

Vereecken, H. 2005. Mobility and leaching of glyphosate: A review. Pest Manag. Sci. $61,1139-1151$

Wauchope, R.D., Yeh, S., Linders, J.B.H.J., Kloskowski, R., Tanaka, K., Rubin, B., Katayama, A., Kördel, W., Gerstl, Z., Lane, M., Unsworth, J.B. 2002. Pesticide soil sorption parameters: Theory, measurement, uses, limitations and reliability. Pest Manag. Sci. 58, 419-445.

Xu, D., Meyer, S., Gaultier, J., Farenhorst, A., Pennock, D. 2009. Land use and riparian effects on prairie wetland sediment properties and herbicide sorption coefficients. J. Environ. Qual. 38, 1757-1765.

Yu, Y., Zhou, Q.X. 2005. Adsorption characteristics of pesticides methamidophos and glyphosate by two soils. Chemosphere 58, 811-816. 
753 Figure 1. Glyphosate adsorption isotherms on soils.

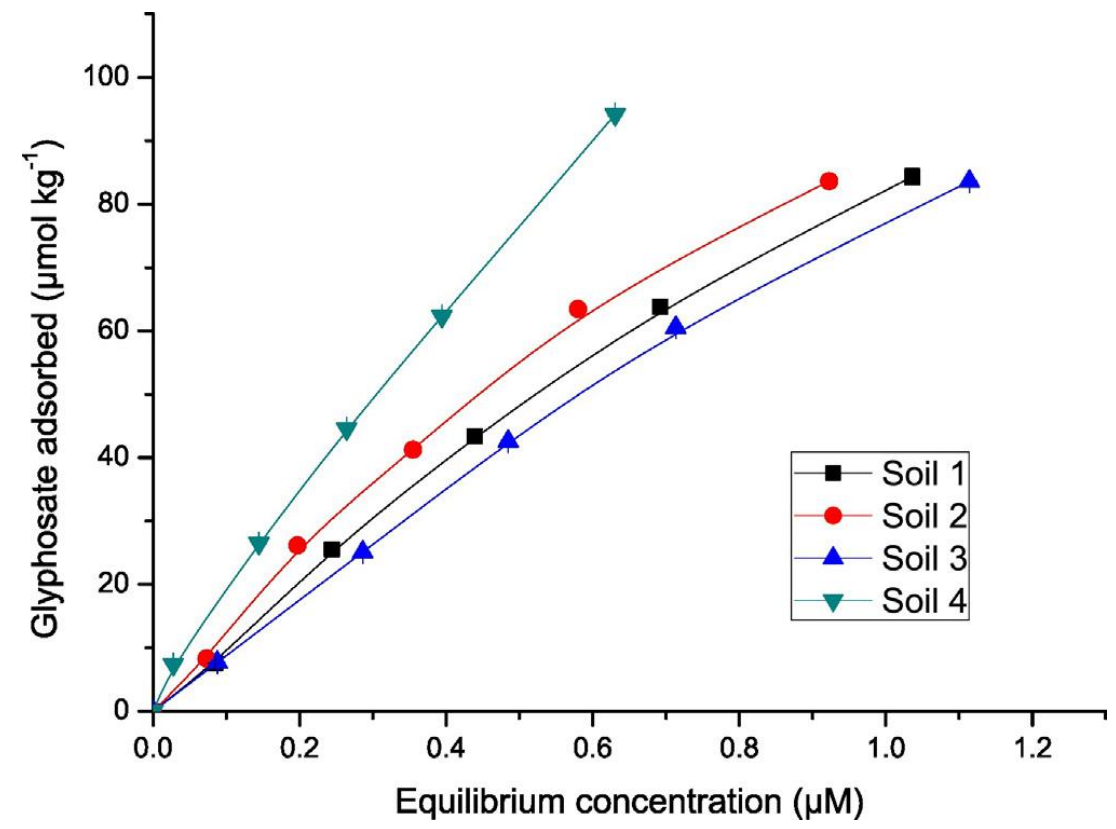

755 Figure 2. Glyphosate adsorption isotherms on sediments: a) Cabecera and Cola
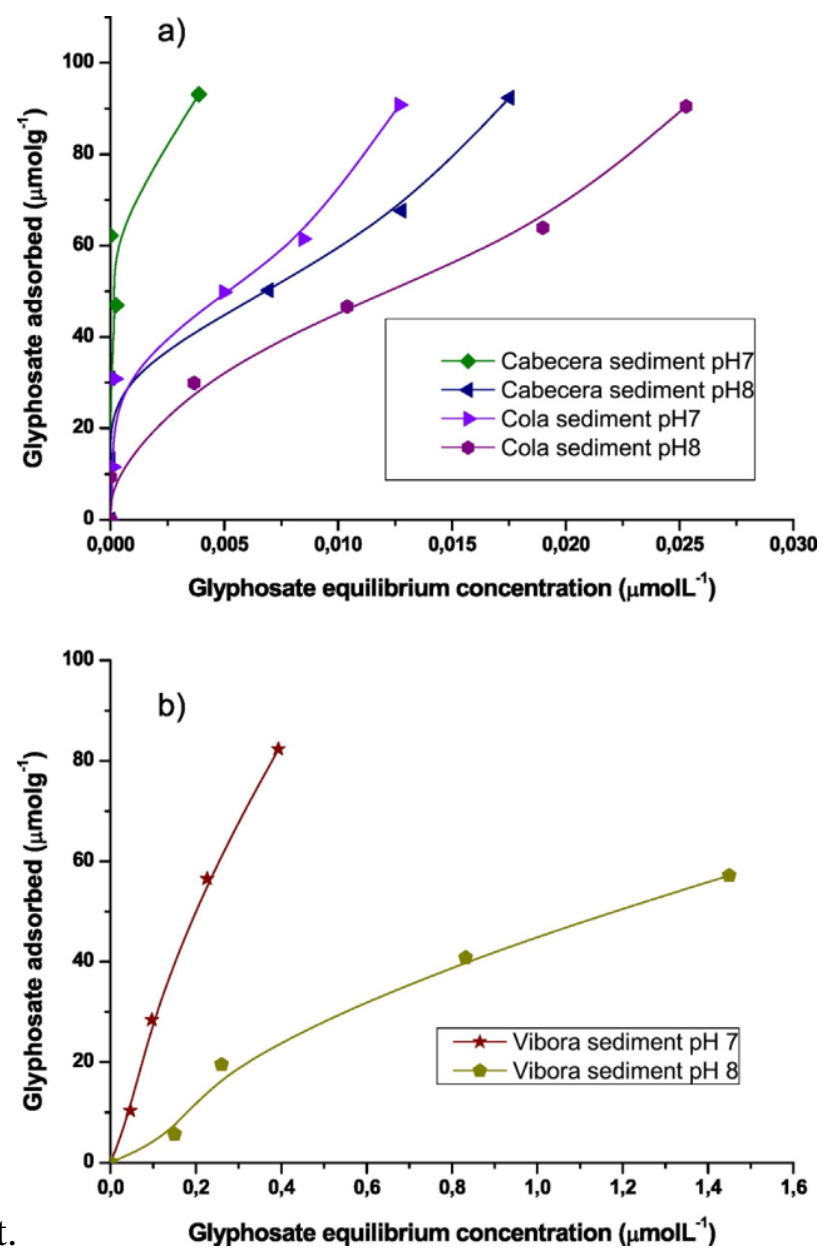

756 sediments; b) Vibora sediment. 
757 Figure 3. GPS dissipation profiles in waters from the Vibora river and from the heading 758 and tail of the reservoir (Cabecera and Cola, respectively).

759

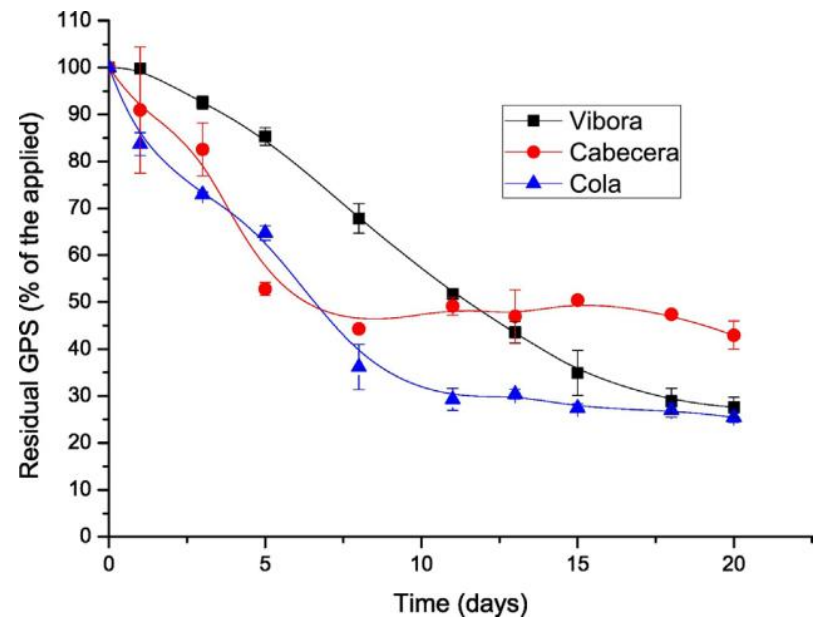

760 G R A P H I C A L A B S T R A C T

Behaviour of Glyphosate in the studied reservoir and surrounding soils

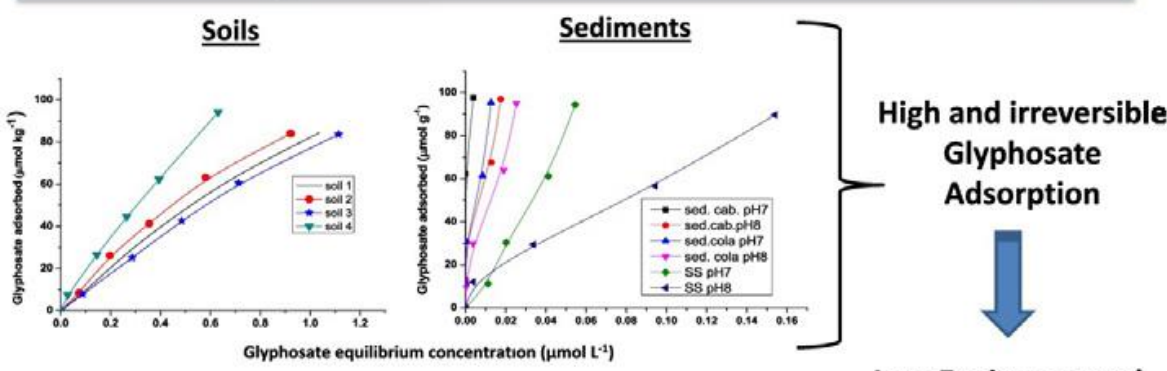

Low Environmental

Viboras reservoir (Jaen, Spain)

Impact
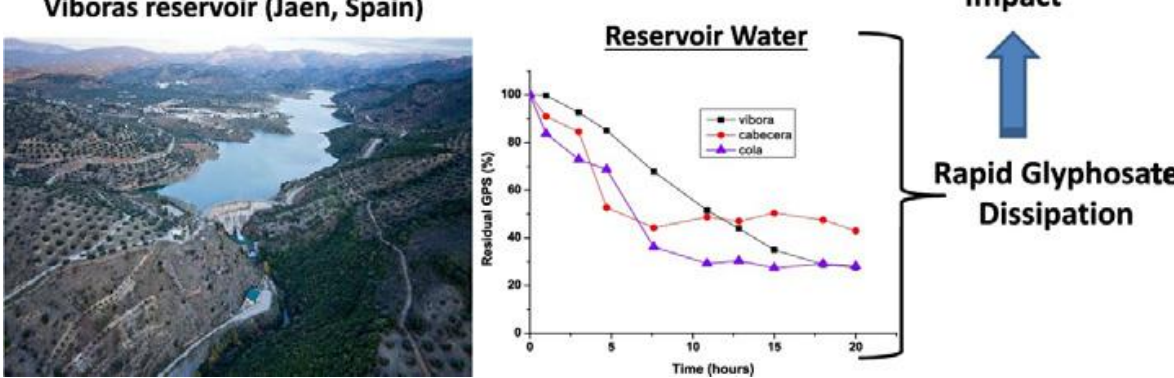

761

Table 1.

Physico-chemical characteristics of the soils and sediments.

Soils

Sediments

$\mathrm{OM}(\%)$

$\mathrm{CaCO}_{3}(\%)$

$\mathrm{pH}$

Clay (\%)

Silt (\%)

Fine sand (\%)

$123 \quad 4$

\begin{tabular}{l|l|l|l|}
1.69 & 1.59 & 1.91 & 1.60
\end{tabular}

34.5

7.65

\begin{tabular}{l|l|l|}
37.6 & 16.2 & 31.5
\end{tabular}

\begin{tabular}{ll|l}
7.73 & 7.47
\end{tabular}

7.48

$36.5 \quad 6.0$

Cola Cabecera Víbora

1.621 .73

22.4

1.52

33.6

31.

31.328

32.2

51

7.34

43.9

8.36

4.9

$\begin{array}{lllllll}6.0 & 11.1 & 8.0 & 10.5 & 42.8 & 31.6\end{array}$

8.0

6.4 
Soils Sediments

\begin{tabular}{|l|l|l|l|l|l|l|l|}
\hline Coarse sand (\%) & 28.5 & 27.0 & 33.5 & 20.8 & - & - & 80.9 \\
\hline Amorphous Fe oxides (\%) & 1.79 & 1.71 & 1.71 & 1.64 & 7.77 & 8.15 & 1.85 \\
\hline Amorphous Al oxides (\%) & 1.16 & 1.33 & 0.83 & 1.76 & 1.71 & 2.16 & 0.43 \\
\hline Amorphous Mn oxides (\%) & 0.19 & 0.21 & 0.34 & 0.38 & 0.13 & 0.18 & 0.15 \\
\hline$\sum$ amorphous oxides (\%) & 3.14 & 3.25 & 2.88 & 3.78 & 9.61 & 10.5 & 2.43
\end{tabular}

764

765

766

767

768

769

770

771

772

773

Table 2.

Semiquantitative estimation (\%) of the clay minerals in soils and sediments. Soils

Sediments

$\begin{array}{llllll}1 & 2 & 3 & 4 & \text { Cola } & \text { Cabecera Vibora }\end{array}$

\begin{tabular}{l|l|l|l|l|l|l|l} 
Illite & 70 & 60 & 80 & 70 & 25 & 40 & 10
\end{tabular}

$\begin{array}{lllllllll}\text { Kaolinite } & 10 & 10 & 5 & 5 & 5 & 5 & <5\end{array}$

\begin{tabular}{l|llllllll} 
Vermiculite & 10 & 15 & 9 & 15 & 5 & 5 & $<5$
\end{tabular}

\begin{tabular}{lllllllll|l} 
Chlorite & 10 & 15 & 6 & - & - & - & -
\end{tabular}

Smectite - $\quad-\quad-10 \quad-\quad-10 \quad-$

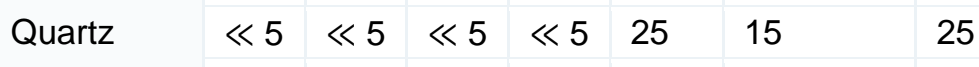

Calcite * * * * * $35 \quad 25 \quad 50$

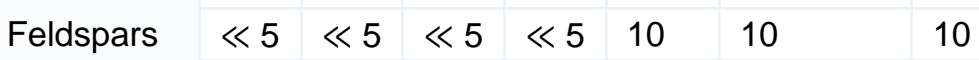

${ }^{*}$ Calcite was not detected in soils because it was previously removed.

Table 3.

Freundlich adsorption isotherm parameter ( $\mathrm{K}_{\mathrm{f}}$ and $\mathrm{n}$ values), coefficients of determination $\left(\mathrm{R}^{2}\right)$ and organic carbon normalized distribution coefficients $\left(\mathrm{K}_{\mathrm{foc}}\right)$ of GPS sorption on the soils. Errors are $<2 \%$.

\begin{tabular}{l|l|l|l|l} 
& $\mathrm{K}_{\mathrm{f}}\left(\mathrm{L} \mathrm{kg}^{-1}\right)$ & $\mathrm{n}$ & $\mathrm{R}^{2}$ & $\mathrm{~K}_{\mathrm{foc}}$ \\
Soil 1 & 91.09 & 0.9654 & 0.987 & 9,295 \\
\hline Soil 2 & 98.06 & 0.8995 & 09876 & 10,659 \\
Soil 3 & 81.39 & 0.9537 & 0.9966 & 7,332 \\
\hline Soil 4 & 132.6 & 0.8109 & 0.991 & 14,263
\end{tabular}

Table 4.

Percentages of GPS desorbed (\%) from the studied soils. Errors are $<2 \%$. GPS initial conc. GPS adsorbed GPS desorbed $\left(\mathrm{mg} \mathrm{L}^{-1}\right) \quad\left(\mu \mathrm{mol} \mathrm{kg}^{-1}\right) \quad(\%)$

\begin{tabular}{|l|l|l|l|}
\hline Soil 1 & 3 & 25.54 & 0 \\
\hline & 5 & 43.46 & 0.40 \\
\hline \multirow{3}{*}{ Soil 2 } & 10 & 84.33 & 0.45 \\
\hline & 3 & 26.17 & 0.52 \\
\hline Soil 3 & 10 & 41.27 & 1.04 \\
\hline \multirow{2}{*}{ Soil 4 } & 3 & 84.0 & 1.22 \\
\hline & 5 & 25.1 & 0.62 \\
\hline & 5 & 42.56 & 1.07 \\
\hline & 10 & 83.59 & 1.18 \\
\hline
\end{tabular}


Table 5.

Distribution coefficients (Kd, $\mathrm{L} \mathrm{kg}^{-1}$ ) of GPS sorption on the soils and sediments. Errors are $<2 \%$.

\begin{tabular}{|l|l|l|} 
& $\mathrm{pH} 7$ & $\mathrm{pH} 8$ \\
\hline Soil 1 & - & 197 \\
\hline Soil 2 & - & 200 \\
\hline Soil 3 & - & 192 \\
\hline Soil 4 & - & 213 \\
\hline Vibora sediment & 404 & 67.3 \\
\hline Cabecera sediment & 11,800 & 6225 \\
\hline Cola sediment & 7961 & 4810 \\
\hline
\end{tabular}

Table 6.

Percentages of GPS desorbed (\%) for the studied sediments at $\mathrm{pH} 8$.

\begin{tabular}{llll} 
& $\begin{array}{l}\text { GPS initial conc. } \\
\left(\mathrm{mg} \mathrm{L}^{-1}\right)\end{array}$ & $\begin{array}{l}\text { GPS adsorbed } \\
\left(\mu \mathrm{mol} \mathrm{kg}^{-1}\right)\end{array}$ & $\begin{array}{l}\text { GPS d } \\
(\%)\end{array}$ \\
Cabecera & 0.25 & 30.83 & 0 \\
\hline \multirow{3}{*}{ Cola } & 1 & 96.96 & 0.97 \\
& 0.25 & 29.90 & 0 \\
\hline \multirow{2}{*}{ Vibora } & 1 & 95.02 & 0.60 \\
& 0.25 & 19.54 & 14.71 \\
& 1 & 57.16 & 19.53
\end{tabular}

Table 7.

Kinetic parameters (k1, k2, tb, and DT50) obtained from glyphosate dissipation in water.

\begin{tabular}{|c|c|c|c|c|c|}
\hline Water & Kinetic model & $\begin{array}{l}\text { K1 } \\
\left(\text { days }^{-1}\right)\end{array}$ & $\begin{array}{l}\text { K2 } \\
\left(\text { days }^{-1}\right)\end{array}$ & $\begin{array}{l}\text { tb } \\
\left(\text { days }^{-1}\right)\end{array}$ & $\begin{array}{l}\text { DT50 } \\
\text { (days) }\end{array}$ \\
\hline Vibora & SFO & 0.06713 & - & - & 10.3 \\
\hline Cabecera & $\mathrm{HS}$ & 0.11012 & 0.00131 & 7.01 & 6.3 \\
\hline Cola & HS & 0.10932 & 0.00637 & 11.0 & 6.4 \\
\hline
\end{tabular}

781 